\title{
Zirconium Dental Implants And Crown for Congenitally Missing Maxillary Lateral; Clinical Case
}

\author{
Abdulgani Azzaldeen, Chlorokostas Georges, Kontoes Nikos, \\ Abu-Hussein Muhamad*
}

\begin{abstract}
Zirconia implants were familiarized into dental implantology. Zirconia appears
to be an appropriate implant material due to its low plaque affinity, tooth like color, biocompatibility and mechanical properties. The following a case presentations will show how the acid-etched zirconia Implant can be used to functionally and aesthetically replace congenitally missing left lateral incisor tooth germ in the maxilla, and achieve optimal soft tissues and health.
\end{abstract}

Keywords: Zirconia, Ceramics, Dental Implants, Aesthetics.

\section{Introduction}

The name "Zirconium" comes from Arabic word "Zargon" meaning "golden in colour". Zirconium dioxide ( $\mathrm{ZrO} 2)$ was accidentally identified by German chemist Martin Heinrich Klaproth [1] in 1789. Subsequently, the impure zirconium was used as a pigment. The first recommended use of Zirconium as a ceramic biomaterial was documented for total hip replacements (THR). In later years, focus was more upon the development of zirconia-yttrium ceramics combinations commonly known as Tetragonal Zirconia polycrystals (TZP). TZP is being used as application in space shuttle, automobiles, cutting tools, and combustion engines because of its good mechanical and dimensional stability, such as mechanical strength and toughness [2,3]. In vitro evaluation of the mutagenic and carcinogenic capacity of the high purity Zirconia ceramic confirmed that it did not elicit such effects on the cells [4] In 1990s, Zirconium material was used as endodontic posts [2] and as implant abutments [4]. This led to the use of Zirconium in dentistry. It has excellent physical properties, white colour, and superior biocompatibility and hence proves to be an esthetic alternative to the metal and porcelain fused to metal crowns and bridges.[1,3]

Zirconium is a polycrystalline ceramic without any glass component. It is a polymorph that occurs in three forms, monoclinic (M), cubic (C) and tetragonal (T). Pure Zirconia at room temperature is in the monoclinic form and stable till $1170{ }^{\circ} \mathrm{C}$. Above this temperature it transforms itself into tetragonal form and then further into cubic phase at $2370{ }^{\circ} \mathrm{C}$. During cooling, a Tetragonal -Monoclinic transformation takes place at the temperature range of about $100{ }^{\circ} \mathrm{C}$ below $1070{ }^{\circ} \mathrm{C}$. [5] The phase transformation, which takes place during cooling, is associated with volume expansion of approximately 3-4\%. Different oxides, such as yttrium oxide (Y2O3), calcium oxide $(\mathrm{CaO})$ or magnesium oxide $(\mathrm{MgO})$, can be added to zirconia to stabilize it, allowing the tetragonal form to exist at room temperature after sintering. The tetragonal zirconia phase is stabilized, but under stress, the phase may change to monoclinic, with a subsequent $3 \%$ volumetric size increase. This dimensional change takes energy away from the crack and can stop it in its tracks.[6] This is called transformation toughening". Also, the volume change creates compressive stress around the particle, which further inhibits crack growth. The addition of varying amounts of stabilizers allows the formation of partially or fully stabilized zirconia which, when combined with changes in processes, may result in ceramics with exceptional properties such as high flexural strength and fracture toughness, high hardness, excellent chemical resistance and good conductivity ions [7].

Ceramic implants are more esthetic and mimic natural teeth better than the grey titanium. Using white ceramic implants would preclude the dark shimmer of titanium implants when the soft periimplant mucosa is of thin biotype or recedes over time. Ceramic materials for oral implants were already investigated and clinically used some 30-40 years ago. [7,8]At that time, the ceramic material utilized was aluminium oxide (polycrystal or single crystal). Currently the material of choice for ceramic oral implants is Y-TZP or Ce-TZP (ceria-stabilized TZP). Compared with alumina, Y-TZP has a higher bending strength, a lower modulus of elasticity and higher fracture toughness [9].

The following a case presentations will show how the acid-etched zirconia Implant can be used to functionally and aesthetically replace congenitally missing left lateral incisor tooth germ in the maxilla, and achieve optimal soft tissues and health.

\section{Case study}


24-year-old patient reported to implant and orthodontics clinic in order to improve the aesthetic look of his teeth within the anterior maxillary section. Clinical examination, confirmed with an X-ray verification revealed lack of congenitally missing maxillary lateral. Fig.1a Fig.1b

Intraoral examination enabled to state a distoposition of tooth 22. The patient commenced an orthodontic treatment with fixed thin archwire appliance aiming to reconstruct the place where it could be possible to insert an implant at the end of the orthodontic therapy. The space in the oral cavity between tooth 21 and tooth 23 was wide enough after 14 months of treatment. A subsequent panoramic X-ray was performed to thoroughly evaluate the available size of the implantation site. Analysis concerning arrangement of teeth revealed a decreased interradicular space between tooth 21 and tooth 23, despite using mesialising bends on the orthodontic arch and changing position of the lock on tooth 21

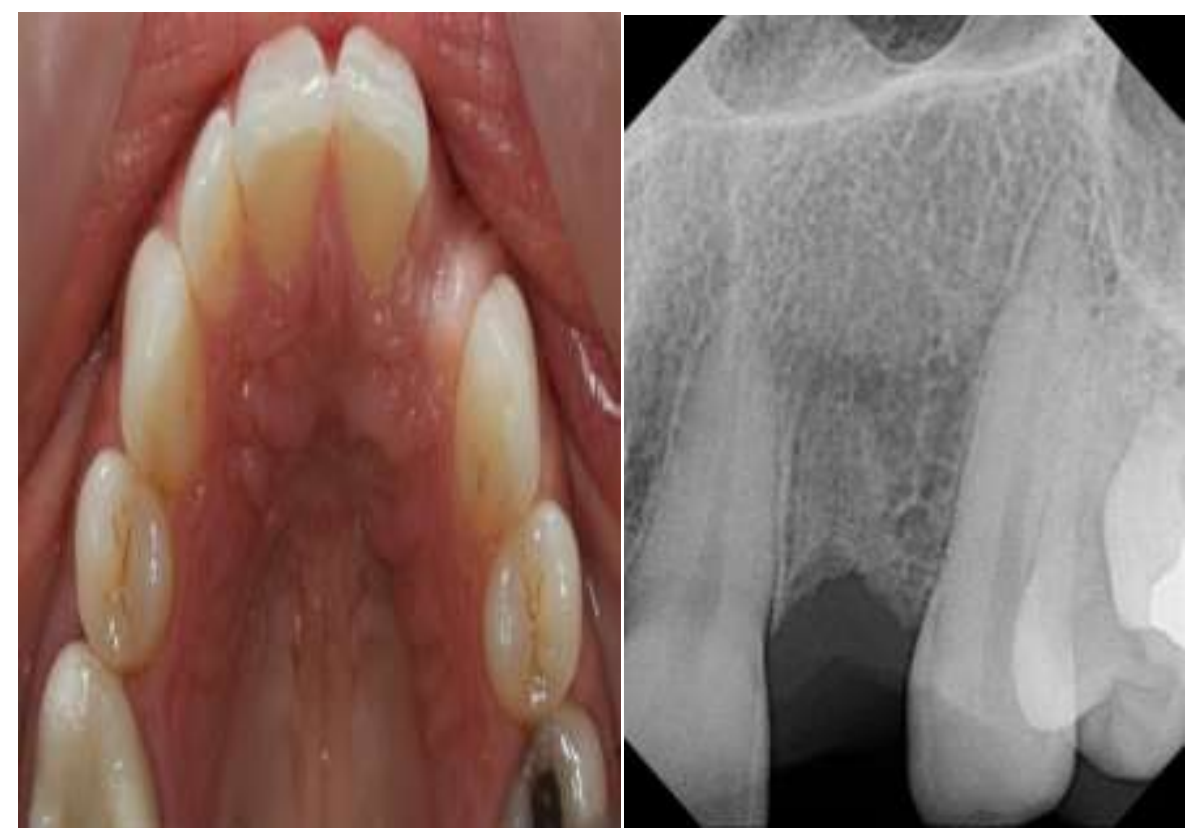

Fig.1a: Pre-operative occlusal view

Fig. 1b: Pre-operative radiograph.

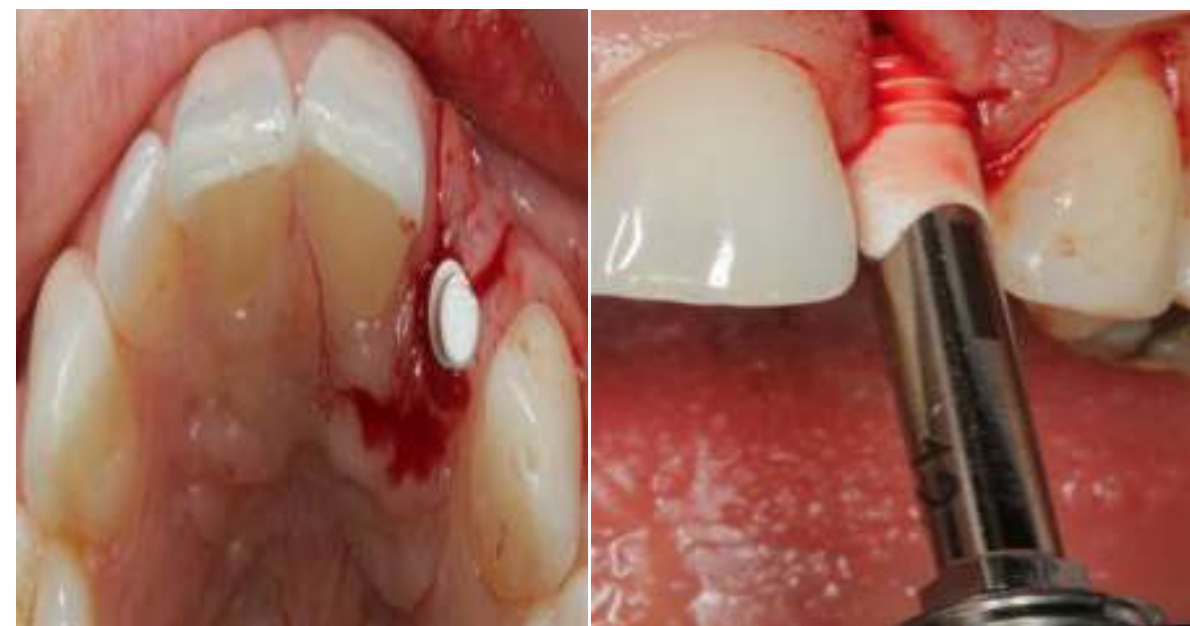

Fig. 2a: Site preparation and drill angulation. Fig.2b;: Implant in site with apical bone exposure

An implant was the preferred treatment option. The possibility of the use of azirconia one-piece dental implant was discussed and the alternative titanium option was also discussed. Due to the high smile line and high esthetic expectation we decided to utilize a zirconia dental implant and an all ceramic E.max crown.The patient was pre-medicated with an antibiotic (Amoxicllin 500mg), which was to be continued for 5 days post operatively . One carpule of four percent articaine 1:200,000 epinephrine was used to anesthetize the operative area. A mini flap was raised sparing the papilla and the osteotomy was preformed utilizing very efficient ceramic drills at 300RPM, the slow drilling helps maintain the vitality of the bone. A closed mouth drilling technique was utilized to allow for ideal angulation. Fig.2a Fig.2b 
Zirconia Implant 12 of $12 \mathrm{~mm}$ length (indicated for upper laterals) implant was selected for this case. The implant was placed at $30 \mathrm{Ncm}$ of initial stability with the buccal restorative margin placed where desired, about $0.5 \mathrm{~mm}$ below the gingival margin. Absorbable sutures were used to stabilize the flap and an immediate provisional crown was fabricated out of a bisacryl and cemented with a small amount of provisional cement.

Fig.3a Fig.3b After three months of healing the soft tissue healed and the implant integrated and was now ready for final restoration A digital scan utilizing was taken and an E.max crown was lab fabricated. Fig.4

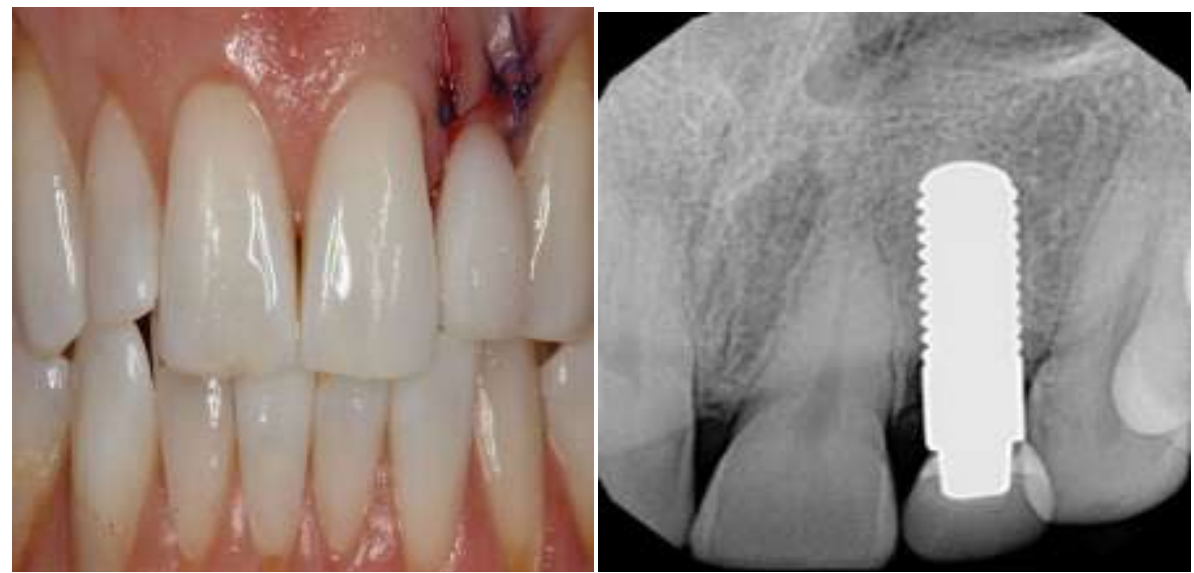

Fig 3a Provisional crown cemented immediately after surgery, Fig 3bPost-operative radiograph.

The crown was tried in and inserted with a composite resin cement, Occlusion was adjusted as to avoid lateral contacts. Special attention was made to adjust the final occlusion of the crown slightly in infraoclusion, avoiding lateral contacts and the anterior guidance. This is important to compensate the elasticity of the periodontium of the neighboring teeth, in contrast of the rigidity of the ceramic implant and crown. The final result, one year after function, shows healthy soft tissue without any signs of inflammation around the Zirconia Implant acid-etched surface Moreover, the periapical radiograph shows that bone is stable around the implant and there is no evidence of early bone remodeling. Fig.5 Fig.6 Fig.7

\section{Discussion}

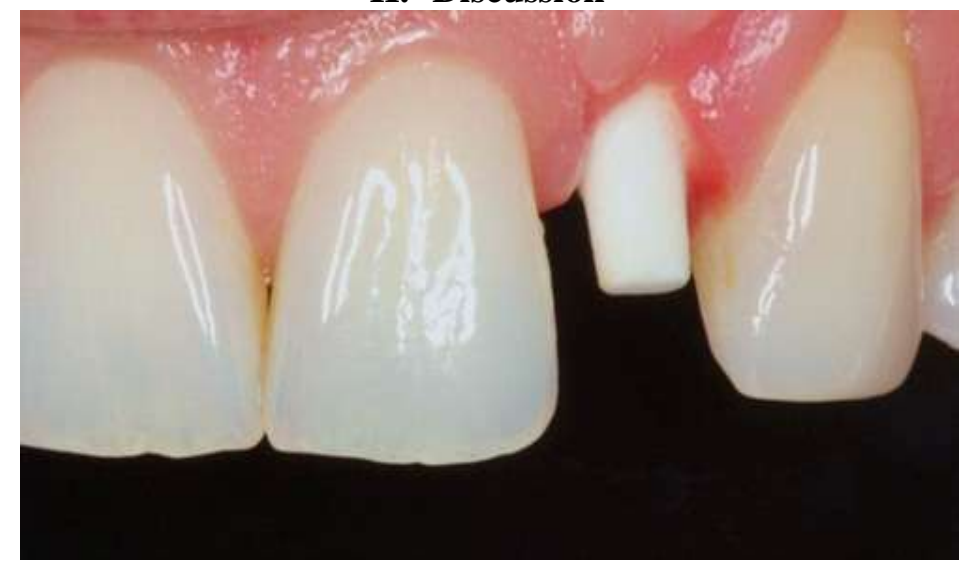

Fig 4;implant three months post surgery.

Modern implantology faced an enormous progress throughout recent years. Implementing intra-osseous implants for reconstructing partial or complete missing teeth is a very well documented treatment method, and the effect of their osseointegration has been thoroughly acknowledged.[10,11] Increasing pressure from patients associated not only with shortening thetreatment time, but also obtaining the best possible aesthetics relating the prosthetic filling, forces doctors to select the most advantageous type of prosthetic filling, as well as to constantly modify the surgical protocol. [12] The necessity to extract at least one tooth and failureto perform prosthetic reconstruction leads to irreversible destructive changes within surrounding hard and soft tissues.[13,14] The fixed prosthetic filling, based on adjoining teeth with the help of cemented combined crowns, is the easiest method to substitute missing teeth.[15] 
However, this type of solution is invasive and can be destructive as far as hard tissues and mash of the neighbouring teeth are concerned [12]. What is more, it does not protect the alveolar bone against reduction concerning the alveolar process. Prosthetic filling basing on intra-osseous implants is the alternative option. An efficient and aesthetic implantation procedure can be performed only with sufficient amount of surrounding and supporting tissues.[16,17] Quite frequently, due to significant loss of alveolar bone, it may be recommended to conduct tissue augmentation, as this leads to its increased width and height [18]. Nonetheless, this procedure is related with additional surgical intervention, which can cause more unanticipated complications, and prolong the period of the whole treatment [14,19]. Implanting a shorter intra-osseous implants, namely short implants, seems to be a good alternative for the above-mentioned surgery [20,21].

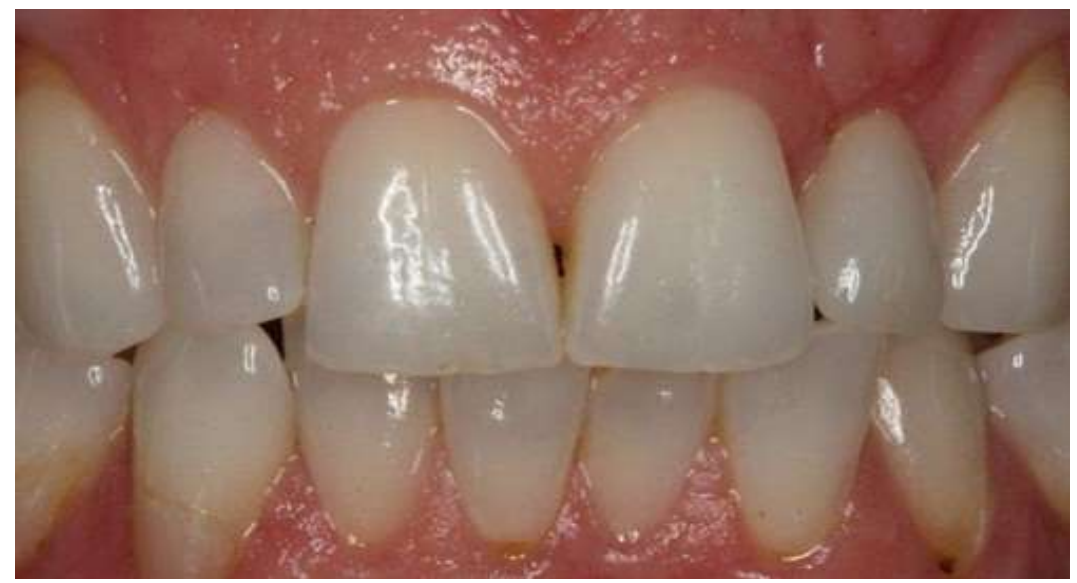

Fig 5;Cementation of final crown.

Zirconia implants are being considered for their advantages of aesthetics, lack of galvanic reactions [1] and lesser risk of inflammation as compared to the accidental introduction of titanium particles in the osteotomy site [2]. Twenty years of evidence has suggested that zirconia based implants are highly biocompatible $[3,4]$ and also possess favourable physical properties [5]. There have been evidences of zirconia being able to withstand long term loads [6], implying that they appear to be satisfactory to use in case of posterior teeth as well.

Allergic reactions to titanium has not been much documented in dental literature. Placing permanent metallic dental implants in allergic patients can cause either Type 1 or Type 4 hypersensitivity reaction [22]. Sicilia A et al., in 2008 studied the prevalence of titanium allergy in 1500 continuous patients and estimated a low prevalence at $0.6 \%$ of all subjects evaluated [23]. The patient in this case report had a history of metal allergy that presented as erythema on wearing artificial jewellery. A clinical report by Egusa $\mathrm{H}$ et al, demonstrated the presence of facial eczema as a result of titanium dental implants. The condition was resolved on removal of the dental implant [24]. There are no case reports reporting zirconia implant placement in a patient with known metal allergy. As the patient did not want any metallic implants; it was decided to use a one piece zirconia implant. The lack of a microgap in single piece implants compared to twopiece dental implants ensures minimal microleakage and bacterial colonization that could result in marginal bone loss [25].

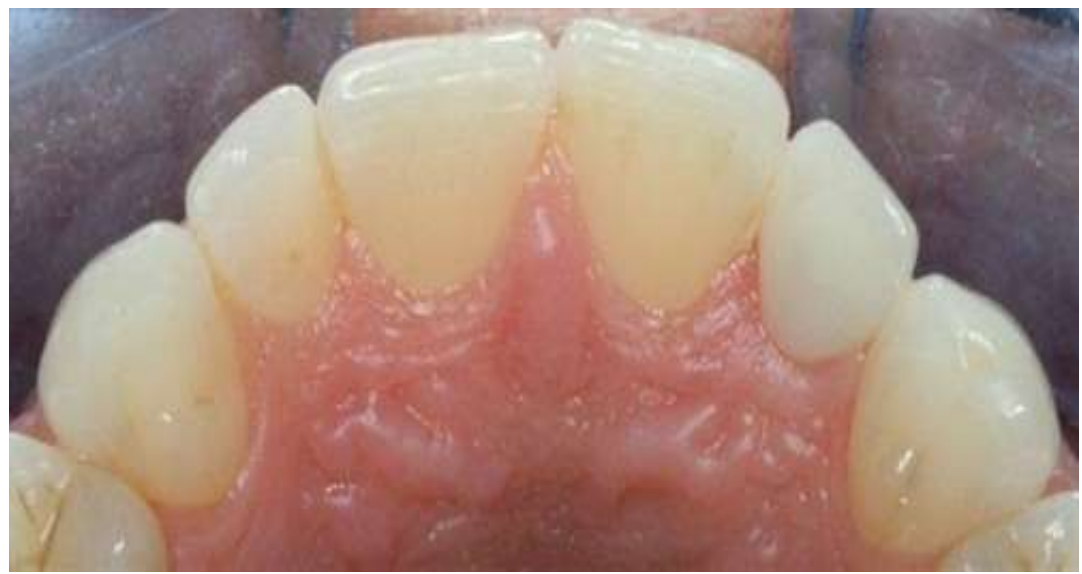

Fig 6; occlusal view

Deprich et al. compared 24 screw type zirconia implants with acid etched surfaces 24 implants of pure titanium with acid etched surfaces [26]. The positive results of ultrastructural evidence of osseointegration of 
both implants were obtained. There was no considerable difference between the implants in terms of stiffness and strength at that time. The osteoblast behaviour on titanium surfaces and zirconia were compared in another examination [27]. Synthesis, rate of proliferation, attachment kinetics of bone associated proteins on each surface was examined and compared in detail. The examination of first day revealed that the zirconia surfaces' cell proliferation was akin to that of titanium surfaces. On the third day, the cell growth was found to be noticeable lower on the titanium surfaces than on the surfaces of zirconium. On the fifth day, cell proliferation went on to be greater on zirconia surfaces in comparison with the titanium surfaces. The last of the studies conducted by the group compared the osseous healing of zirconia implants with that of acid etched titanium implants having same macroscopic design. At first, fourth or twelfth week, BIC was a little better on titanium in comparison with zirconia surfaces. But there was no vast statistical difference between the groups. The results showed that the zirconia implants with altered surfaces caused an osseointegration which could be compared with the likes of titanium implants [28].

Silva et al. examined effects of full crown preparations on reliability of 1-piece zirconia implants [29]. They observed that zirconia implants' fracture strength without preparation was $1023.3 \mathrm{~N}$ and with full crown preparation it was $1111.7 \mathrm{~N}$. But another study concluded that the preparation of implant heads showed considerably negative influence on fracture strength of implant. Fracture strength of 1-piece zirconia implants after exposure to artificial mouth with clinical service of five years was estimated. Zirconia implant fracture was observed at 725- $850 \mathrm{~N}$ without implant head preparation. They concluded that mean fracture strength for zirconia implants fell within clinical acceptance limits [39]. Kohal et al. presented a first clinical case report of zirconia dental implant [31]. A custom built two-piece zirconia implant replaced a left upper central incisor with the zirconia abutment and zirconia single crown. Additionally, Oliva et al. reported a first clinical case of ovoid zirconia implant. A specially designed, anatomically oriented ovoid zirconia implant was used to replace missing premolar was discussed [32].

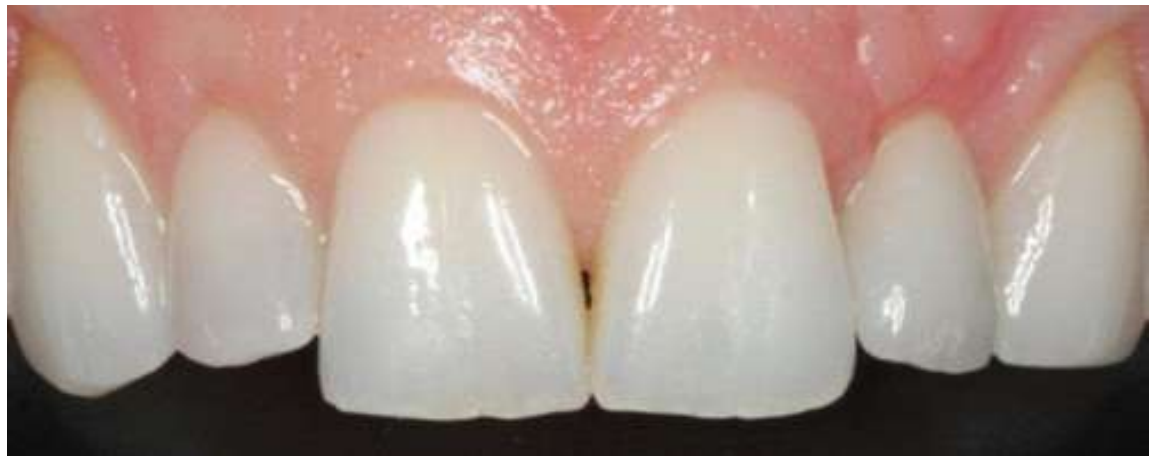

Fig7; Cement retained implant supported zirconia fused to porcelain crown at 6months post op.

Blaschke et al. noted that zirconia dental implants were feasible alternatives to titanium implants [33]. Along with superb cosmetic results, zirconia implants permit a degree of osseointegration and soft tissue response superior to titanium implants. Olivia et al. report the first clinical evaluation on hundred zirconia implants with two different surface roughness in humans after one year follow-up. Two of these failed after fifteen days. These were placed where sinus elevation was needed. Success rates were reported to be $98 \%$. Given the requirement of sinus elevation, future researchers may exclude patients having residual bone less than $5 \mathrm{~mm}$. Picker et al. put a zirconia implant at maxillary first premolar region and evaluated clinical outcome of the implant. After a two year follow up, stable implant and unaltered pen-implant marginal bone levels were noted. There was no bleeding on probing [34,35]. The great aesthetic potential, restorative simplicity and surface roughness make this system ideal for immediate tooth replacement. Periodontal health is amplified by the absence of a connection and microgap, and the affinity of the gingival complex to the zirconia oxide surface. Long-term success has been demonstrated in the literature. Case selection is crucial as ideal angulation is imperative.

\section{Conclusion}

Zirconia dental Implants in this cases report is based on valid scientific basis and may be considered as a new approach to optimise aesthetic outcome of immediate replacement technique in the aesthetic zone.

\section{References}

[1]. Piconi C, Maccauro G. Zirconia as ceramic biomaterial. Biomaterials. 1999;20:1-25. 
[2]. Pilathadka S., Vahalová D., Vosáhlo T. The Zirconia: a New Dental Ceramic Material. An Overview. Prague Med Report. 2007; 108(1): 5-12

[3]. Edward A McLaren, Russell A Giordano. Zirconia-Based Ceramics: Material Properties, Esthetics, and Layering Techniques of a New Veneering Porcelain, VM9. Quint Dental Technol. 2011; 99-111

[4]. Ahmad A Jum'ah, Bart MN Beekmans, David J Wood, Hassan Maghaireh. Zirconia Implants: The New Arrival in the Armoury of Successful Aesthetic Implant Dentistry. Smile Dental J. 2012; 7(2): 12-26

[5]. 5.Brüll F, van Winkelhoff AJ, Cune MS (2014) Zirconia dental implants: a clinical, radiographic, and microbiologic evaluation up to 3 years. Int J Oral Maxillofac Implants 29: 914-20.

[6]. Apratim A, Eachempati P, Salian KKK, Singh V, Chhabra S (2015). Zirconia in dental implantology: A review. J Int Soc Prev Community Dent. 5: 147-156.

[7]. Kohal R, Klaus G (2004) A zirconia implant-crown system: a case report. Int J Periodontics Restorative Dent 24: 147-153.

[8]. Christel P, Meunier A, Heller M,Torre JP, Peille CN. Mechanical properties and short-term in vivo evaluation of yttrium oxidepartially-stabilized zirconia. J Biomed Mater Res 1989;23:45-61.

[9]. Gupta TK, Lange FF, Bechtold JH. Effect of stress-induced phase transformation on the properties of polycrystalline zirconia containing metastable tetragonal phase. J Mater Sci 1978;13:1464-1470.

[10]. Abu-Hussein M., Abdulgani A., Watted N .Zahalka M.; Congenitally Missing Lateral Incisor with Orthodontics, Bone Grafting and Single-Tooth Implant: A Case Report. Journal of Dental and Medical Sciences2015, 14(4),124-130

[11]. Abdulgani A.,. Kontoes N., Chlorokostas G.,Abu-Hussein M .; Interdisciplinary Management Of Maxillary Lateral Incisors Agenesis With Mini Implant Prostheses: A Case Report; IOSR-JDMS 2015,14 (12), 36-42

[12]. Abu-Hussein Muhamad Chlorokostas Georges, Abusalih Ahmet, Ismail Hakki Bayraktar, Abdulgani Azzaldeen; Immediate Implant Placement and Loading in Esthetic Zone. Journal of Dental and Medical Sciences 2016 ,1, 71-79,DOI: 10.9790/085315187179

[13]. Nezar Watted, Muhamad Abu-Hussein ;Multidisciplinary Aesthetic Dental Treatment; Peg lateral with Congenitally Maxillary lateral Incisors. Journal of Dental and Medical Sciences 2016, 15, 10, 83-91,DOI: 10.9790/0853-1510018391

[14]. Muhamad AH, Azzaldeen A, Nezar W, Mohammed Z. ; Esthetic Evaluation of Implants Placed after Orthodontic Treatment in Patients with Congenitally Missing Lateral Incisors. J Adv Med Dent Scie Res2015 ;3(3):110-118

[15]. Abusalih A. , Ismail H, Abdulgani A. ,Chlorokostas G ., AbuHussein M .; Interdisciplinary Management of Congenitally Agenesis Maxillary Lateral Incisors: Orthodontic/Prosthodontic Perspectives, Journal of Dental and Medical Sciences2015 ,15 ( 1 ) , $90-99$ DOI: $10.9790 / 0853-15189099$

[16]. Abu-Hussein M, Chlorokostas G, Watted N, Abdulgani A, Jabareen A; PreProsthetic Orthodontic Implant for Management of Congenitally Unerupted Lateral Incisors - A Case Report. J Dent Med Sci2016, 15: 99-104.

[17]. Abu-Hussein M, Watted N, Abdulgani A ;Managing congenitally missing lateral incisors with single tooth implants. Dent Oral Craniofac Res 20162: 318-324.

[18]. Mai A, Azzaldeen A, Nezar W, Chlorokostas G, Muhamad AH; Extraction and Immediate Implant Placement with SingleStageSurgical Procedure: Technical Notes and a Case Report. J Dent Med Sci2016, 15: 95-101

[19]. Abu-Hussein M, Georges C, Watted N, Azzaldeen A ;A Clinical Study Resonance Frequency Analysis of Stability during the Healing Period. Int J Oral Craniofac Sci 2016,2(1): 065-071. DOI: 10.17352/2455-4634.000021

[20]. Abu-Hussein M, Watted N, Shamir D ;A Retrospective Study of the AL Technology Implant System used for Single-Tooth Replacement. Int J Oral Craniofac Sci 2016,2(1): 039-046. DOI: 10.17352/2455-4634.000017

[21]. Abdulgani Mai, Abdulgani Azzaldeen, Watted Nezar ,Chlorokostas Georges ,Abu-Hussein Muhamad;Extraction and Immediate Implant Placement with Single-Stage Surgical Procedure: Technical Notes and a Case ReportJournal of Dental and Medical Sciences Volume 2016 , 15, Issue 11 ,95-101,DOI: 10.9790/0853-15110195101

[22]. Siddiqi A, Payne AG, De Silva RK, Duncan WJ. Titanium allergy: could it affect dental implant integration?. Clin Oral Implants Res. 2011, Jul; v.22(7), p.673-80. doi: 10.1111/j.1600-

[23]. 0501.2010.02081.

[24]. Sicilia, A.; Cuesta, S.; Coma, G.; Arregui, I.; Guisasola, C.; Ruiz, E.; Maestro, A. Titanium allergy in dental implant patients: A clinical study on 1500 consecutive patients. Clin. Oral Implants Res. 2008, 19, 823-835.

[25]. Egusa H, Ko N, Shimazu T, Yatani H. Suspected association of an allergic reaction with titanium dental implants: A clinical report. The Journal of Prosthetic Dentistry. 2008;100(5):344-47

[26]. Borgonovo AE, Fabbri A, Vavassori V, Censi R, Maiorana C. Multiple teeth [9] replacement with endosseous one-piece yttriumstabilized zirconia dental implants. Med Oral Patol Oral Cir Bucal. 2012;17(6):e981-87

[27]. Depprich R, Zipprich H, Ommerborn M (2008) Osseointegration of zirconia implants: an SEM observation of the bone-implant interface. Head Face Med 4: 25.

[28]. Depprich R, Ommerborn M, Zipprich H (2008) Behavior of osteoblastic cells cultured on titanium and structured zirconia surfaces. Head Face Med 4: 29.

[29]. Depprich R, Zipprich H, Ommerborn M (2008) Osseointegration of zirconia implants compared with titanium: an in vivo study. Head Face Med 4: 30.

[30]. Silva NR, Coelho PG, Fernandes CA, Navarro JM, Dias RA, et al. (2009)

[31]. Reliability of one-piece ceramic implant. J Biomed Mater Res B Appl Biomater 88: 419-426.

[32]. Andreiotelli M, Kohal RJ (2009) Fracture strength of zirconia implants after artificial aging. Clin Implant Dent Relat Res 11: 158166.

[33]. Kohal RJ, Klaus GA (2004) Zirconia implant-crown system: a case report. Int J

[34]. Periodontics Restorative Dent 24: 147-153.

[35]. Oliva J, Oliva X, Oliva JD (2008) Ovoid zirconia implants: anatomic design for premolar replacement. Int J Periodontics Restorative Dent 28: 609-615.

[36]. Blaschke C, Volz U (2006) Soft and hard tissue response to zirconium dioxide ental implants-a clinical study in man. Neuroendocrinol Lett. 27: 69-72.

[37]. Oliva J, Oliva X, Oliva JD (2007) One-year follow-up of first consecutive 100 zirconia dental implants in humans: a comparison of 2 different rough surfaces. Int J Oral Maxillofac Implants 22: 430-435.

[38]. Pirker W, Kocher A (2008) Immediate, non-submerged, root-analogue zirconia implant in single tooth replacement. Int J Oral Maxillofac Surg 37: 293-295. 